\title{
Effects of multimodal agility-like exercise training compared to inactive controls and alternative training on physical performance in older adults: a systematic review and meta-analysis
}

\author{
Mareike Morat ${ }^{1}$, Tobias Morat ${ }^{2}$, Wiebren Zijlstra ${ }^{2}$ and Lars Donath ${ }^{1^{*}}$
}

\begin{abstract}
Background: Multimodal exercise training (MT) as a time-efficient training modality promotes a wide range of physical dimensions. Incorporating agility-like training aspects (coordination, changes of direction and velocity) into MT may further enhance physical outcomes highly relevant for activities of daily living. This meta-analysis investigated the effects of multimodal agility-like exercise training (MAT) on physical and cognitive performance compared to inactive (IC) and active controls (AC) in older adults.

Methods: Literature search was conducted in four health-related databases (PubMed, SCOPUS, SPORTDiscus and Web of Science). Randomized controlled trials with pre-post testing applying MAT (including aspects of training with at least two different traditional domains: strength, balance, endurance) and an agility-like component in community-dwelling older adults were screened for eligibility. Standardized mean differences (SMD) adjusting for small sample sizes (hedges' g) were used to extract main outcomes (strength, gait, balance, mobility, endurance, cognition). Statistical analysis was conducted using a random effects inverse-variance model.

Results: Twenty trials with 1632 older adults were included. All effects were significantly in favour of MAT compared to IC: Strength, mobility and endurance revealed large overall effects (SMD: 0.88, 0.84, 1.82). Balance showed moderate effects (SMD: 0.6). Small overall effects were observed for gait (SMD: 0.41). Few data were available to compare MAT vs. AC with negligible or small effects in favour of MAT. Funnel plots did not reveal clear funnel shapes, indicating a potential risk of bias.

Conclusions: MAT may serve as a time-efficient training modality to induce positive effects in different physical domains. Compared to isolated training, MAT allows equal effect sizes at lower overall training volumes. More studies are needed to investigate the potential value of MAT with systematic training and load control, especially compared to other exercise-based interventions.
\end{abstract}

Keywords: Agility-like training, Agility inspired training, Multimodal exercise training, Meta-analysis

\footnotetext{
* Correspondence: I.donath@dshs-koeln.de

'Institute of Exercise Training and Sport Informatics, Department of

Intervention Research in Exercise Training, German Sport University Cologne,

Am Sportpark Muengersdorf 6, 50933 Cologne, Germany

Full list of author information is available at the end of the article
}

(c) The Author(s). 2021 Open Access This article is licensed under a Creative Commons Attribution 4.0 International License, which permits use, sharing, adaptation, distribution and reproduction in any medium or format, as long as you give appropriate credit to the original author(s) and the source, provide a link to the Creative Commons licence, and indicate if changes were made. The images or other third party material in this article are included in the article's Creative Commons licence, unless indicated otherwise in a credit line to the material. If material is not included in the article's Creative Commons licence and your intended use is not permitted by statutory regulation or exceeds the permitted use, you will need to obtain permission directly from the copyright holder. To view a copy of this licence, visit http://creativecommons.org/licenses/by/4.0/. The Creative Commons Public Domain Dedication waiver (http://creativecommons.org/publicdomain/zero/1.0/) applies to the data made available in this article, unless otherwise stated in a credit line to the data. 


\section{Introduction}

The worlds' population is gradually ageing due to an increasing life expectancy [1]. Living those gained years without or with less disabilities requires a health care system focusing on physical, cognitive, and psychosocial wellbeing from a preventive and multidisciplinary perspective [2]. Regular physical activity can attenuate the risk of multiple ageing related diseases [3]. To improve or maintain adequate physical and cognitive performance, exercise training needs to be challenging and multimodal. Since training-induced adaptations have been reported to be very task- and exercise-specific [4, 5], selectively addressing the many dimensions of physical and cognitive performance does not reflect the integrative character of everyday life situations [6].

Established exercise training guidelines for older adults comprise a variety of separate recommendations for relevant main training domains: endurance, strength, balance, and flexibility training [7]. Highly topical, the recently published "guidelines on physical activity and sedentary behaviour" by the World Health Organization (WHO) also take up these aspects. Besides aerobic physical activity, the WHO proposes muscle-strengthening activities that involve all major muscle groups on at least 2 days a week for additional health benefits and varied multicomponent exercises with focus on functional balance and strength training to enhance functional capacity and to prevent falls [8]. The latest CochraneReview on fall prevention [9] showed reductions of the rate of falls and the number of fallers by implementing balance exercises combined with functional exercises and by multi-component exercise interventions including balance, functional and strengthening exercises. This also supports a multimodal exercise training (MT) approach, combining different training domains. Furthermore, an approach combining gait, balance and functional training was already set as one of the categories to classify and describe fall-prevention interventions in the taxonomy for exercise interventions by the Prevention of Falls Network Europe (ProFaNE) in 2011 [10]. MT seems particularly essential, since subjectively perceived "lack of time" is among the most reported barriers for the uptake and maintenance of exercise training programs in (older) adults and adherence decreases with every additional weekly training session $[3,11]$. Thus, exercise training needs to be time efficient and should integratively train all relevant physical and cognitive performance domains.

For an integratively promotion of balance, strength, and endurance with functional, progressive exercises, combined start-stop and change of direction movements, Donath and colleagues [12] proposed an agilitybased exercise training framework for fall prevention for older adults. Within the framework, complex functional tasks, including perception, decision making, reaction, and changes of direction are considered. Task complexity and difficulty are progressively increased in a supervised, group-based training setting. The underlying exercises can vary by changes of the physical, perceptual, or cognitive demands of each exercise or a combination of exercises. Higher physical and cognitive demands also enable cardiovascular and cognitive training stimuli, respectively [12].

However, the term "agility" is not established across literature with older adults, yet. Some intervention studies that designed their training considering aspects of the agility framework used different wording. Those studies refer to group-based exercise training twice or three times per week including multiple physical training components and agility-like aspects. Improvements in strength [13-15], balance [16, 17], cognition [18] and endurance performance $[14,17]$ were then reported, whereas the greatest improvements have been found in functional mobility outcomes $[14,15,19]$.

Based on our knowledge, the agility-based exercise training framework by Donath et al. [12] was not extensively implemented in fall prevention programmes for older adults, yet, but there are several studies that already included some aspects of this framework with older adults not being at high risk for falls [13-19]. However, to date, no meta-analytical evaluation of the effects of multimodal agility-like exercise training (MAT) in older adults has been conducted.

Against this background, the objectives of this metaanalysis are to calculate and classify the effects of MAT compared to an inactive (IC) and/or active control (AC) condition regarding physical (lower and upper body strength, overall strength, gait, balance, mobility, endurance) and cognitive performance in community-dwelling older adults, to describe the present training characteristics of MAT for older adults and to provide recommendations for future research and exercise training practice.

\section{Methods}

\section{Protocol and registration}

This meta-analysis was conducted according to the PRIS MA guidelines [20]. This meta-analysis was registered in PROSPERO: CRD42020157205.

\section{Search strategy and study selection}

Literature search was conducted in four health-related databases (PubMed, SCOPUS, SPORTDiscus and Web of Science) until November 21st, 2020. Boolean conjunctions (OR/AND/NOT) were used to combine relevant search terms (operators). These were applied on three search levels (see Table 1). 
Table 1 Levels and terms of the literature search process

\begin{tabular}{|c|c|}
\hline $\begin{array}{l}\text { Search } \\
\text { level }\end{array}$ & Search terms with Boolean operators \\
\hline Search \#1 & (intervention OR interventional OR interventions OR training OR exercise OR exercising OR exercises) \\
\hline Search \#2 & $\begin{array}{l}\text { \#1 AND (multimodal training OR multi-modal training OR multi-component training OR multicomponent training OR multimodal inter- } \\
\text { vention OR multi-modal intervention OR multi-component intervention OR multicomponent intervention OR multimodal exercise OR } \\
\text { multi-modal exercise OR multi-component exercise OR multicomponent exercise OR multimodal exercises OR multi-modal exercises OR } \\
\text { multi-component exercises OR multicomponent exercises OR resistance OR strength OR strengthening OR power OR weight-bearing } \\
\text { OR speed OR sprint OR balance OR balancing OR coordination OR coordinative OR posture OR postural OR proprioceptive OR proprio- } \\
\text { ception OR sensorimotor OR sensorimotoric OR sensori-motor OR sensori-motoric OR instability OR perturbed OR perturbation OR per- } \\
\text { turbations OR cognitive OR cognition OR endurance OR aerob OR aerobic OR cardiologic OR cardio OR cardiovascular OR cardio- } \\
\text { vascular OR agile OR agility) }\end{array}$ \\
\hline Search \#3 & \#2 AND (senior OR seniors OR elder OR aged OR elderly OR old OR older OR aging OR ageing) \\
\hline Search \#4 & $\begin{array}{l}\text { \#3 NOT ((patients OR patient) NOT disease NOT stroke NOT diabetes NOT neuropathy NOT amputation NOT multiple sclerosis NOT } \\
\text { cerebral palsy NOT parkinson NOT neoplasms NOT cancer NOT obesity NOT obese NOT osteoarthritis NOT fractures NOT fracture NOT } \\
\text { physiopathology NOT dysfunction NOT cognitively impaired NOT frail NOT demented NOT pilot study NOT rheuma NOT rheumatic } \\
\text { NOT rheumatoid NOT dietary NOT supplements NOT dietary supplements NOT supplementation NOT drugs NOT abuse) }\end{array}$ \\
\hline
\end{tabular}

Hand searching within primary articles and review articles was additionally carried out. All duplicates were removed, before the remaining studies underwent manual screening on three screening levels: 1) title, 2) abstract and 3) full-text. Two independent researchers (MM, TM) conducted the entire process. Irrelevant articles were excluded according to the following criteria. Both researchers achieved a final consensual decision.

The following inclusion criteria were applied for manual screening of the studies:

- Full-text article from peer-reviewed journals in English language

- Randomized controlled intervention study with prepost testing

- One or more control group(s), receiving no intervention (= inactive control group, IC) and/or receiving an alternative exercise-based training program (= active control group, AC)

- Participants were community-dwelling older adults

- Participants mean age of 65 years or older

- Multimodal exercise training intervention that included aspects of training with at least two different domains (strength, balance, endurance) and an agility-related component (coordination or change of direction and velocity)

- Exercise intervention lasting for at least 6 weeks with a minimum of two weekly training sessions

- Exercise training in a supervised group setting

- Outcome measures that included at least one of the following domains: strength, gait, mobility, balance, endurance, cognition

The following exclusion criteria were applied for manual screening of the studies:

- Older adults with mental declines, acute and chronic cardiac, orthopaedic and/or neurologic conditions
- Competing (master) athletes

- Hospitalized and/or institutionalized older adults

- Older adults at risk of falling or with a serious fall event that led to medical attention (e.g. broken bones) within 1 year prior to the start of the study

- Intervention including nutritional supplementation

- Technology-based intervention

- Study without a comparison group

\section{Assessment of methodological quality}

Methodology of the included studies was rated using the PEDro scale obtained from the Physiotherapy Evidence Database [21]. It comprises 11 dichotomous items (either yes $=1$ or no $=0$ ). However, only ten items will be summed up to the final score. Two researchers (MM, TM) independently rated all included studies and arrived at consensus on every item after completing the individual rating process. Raters were not blinded to the study authors and results.

\section{Data extraction and synthesis}

Two researchers (MM, TM) extracted the following primary or secondary outcome domains:

- overall strength (lower body and upper body strength)

- gait

- balance

- mobility

- endurance

- cognition

For strength, isokinetic, isometric and dynamic strength measurements, jumps and tests for muscular endurance (e.g. push-ups, sit-ups) were considered. Assessments, measuring gait speed over a defined distance were taken into account for the gait domain [10]. Balance measures comprised all assessments that determine 
balance (different stance positions on firm and uneven surfaces, dynamic walks e.g. tandem walk, the functional reach test or test batteries [e.g. Berg Balance Scale] [10]. Mobility tests were chosen as such tests, that depict activities of daily living and are not solely assignable to one of the other domains such as the Timed Up and Go Test (TUG) as a measure of performance including dynamic balance and mobility and the Sit to Stand Test (STS) examining lower body muscle function [22], figure- of- 8 running, maximum step length test and the completion of obstacle courses. The successful performance of the included tests is determined by several factors like the STS, which was shown to represent a particular transfer skill, rather than a proxy measure of lower limb strength influenced by multiple physiological and psychological processes [23]. For endurance, the 6 min walk test and the 2 min step test were involved. Cognition comprises all emerging measures that are entitled as such in the respective articles.

Data were transferred to an excel spreadsheet. Relevant study information such as authors, publication year, study design, sample size, gender and mean age of participants, groups and group size, training characteristics, training design, load control and progression, outcome measures, adverse events, adherence rates were extracted. Groups were considered as IC when participants received no treatment at all and as AC when they received any other treatment as MAT. In two studies, one of two AC had to be chosen for further analysis. Resistance training was selected over balance [14] and over coordination [15] training, because resistance training was part of most of the $\mathrm{AC}$ of other relevant studies and thus, the homogeneity of $\mathrm{AC}$ was higher.

We grouped all active, exercising control groups $(n=$ 247), leaving out the PC training group. In case of missing outcome data, authors were contacted via email and asked to provide relevant means with standard deviations. If no answer were received, the respective results could not be integrated in this meta-analysis. If two published articles were included that clearly originated from the same study with the same sample, both articles were merged and treated as one for data analysis to avoid overrepresentation of study results.

\section{Statistical analysis}

For each study, standardized mean differences (SMD, with $90 \%$ confidence intervals [CIs]) were computed separately. Therefore, the difference of the target outcome measure between the intervention and the respective control condition including the pooled standard deviations were computed for each outcome. If one study reported several outcome measures of one domain, effect sizes and standard errors were pooled. An inverse-variance method was computed according to
Deeks and Higgins [24]. Analyses were conducted applying a random effects model [25]. Forest plots were built for the respective outcome measure category. The following scale was used to classify the magnitude of SMD: $0-0.19=$ negligible effect, $0.20-0.49=$ small effect, 0.50 $0.79=$ moderate effect and $0.80=$ large effect [26]. Study heterogeneity was assessed using $I^{2}$ [27]. A qualitative funnel plot evaluation was performed to assess the risk of a potential bias [28]. All statistical analyses were computed using the Cochrane Review Manager Software (RevMan 5.3, Cochrane Collaboration, Oxford, UK).

\section{Results \\ Trial flow}

Twenty-seven thousand five hundred sixteen potentially relevant articles were found (see Fig. 1). Twenty-one thousand one hundred sixty article titles were cautiously screened for relevance after removing duplicates. One thousand seven hundred fifty potentially relevant articles remained for abstract screening. After thoroughly studying the abstracts, 204 full-texts were further reviewed. One hundred eighty-four did not meet the inclusion or were excluded according to the exclusion criteria. Two additional articles were obtained from reviews leading in total to 22 studies that were finally included in the quantitative meta-analysis. In two cases [29-32], two articles were based on the same study with identical samples. Thus, the two studies were merged respectively and integrated as one study in each case during the further steps of the meta-analysis. They are presented as Ansai et al. $[29,30]$ and Lord et al. [31, 32] respectively, resulting in a total of 20 studies for analysis. Two other articles also originated from the same study, but different intervention periods were examined, so that the more recent study was selected for analysis [33, 34]. All studies were published 1995 or later. Three studies did not report all relevant data as means \pm standard deviations [18, 35, 36]. Authors were contacted and asked to provide missing data. One author [36] answered the request, so that one dataset for balance performance [35] and one dataset for endurance performance [18] had to be left out of further analysis.

\section{Study population and quality}

In the 20 studies, 1632 community-dwellers with a mean age of $72.4 \pm 4.3$ years were assessed (see Table 2). The sample size ranged from 32 [34] to 259 [18] participants, with a mean size of $82 \pm 64$ participants. The sample sizes among the studies were not normally distributed (Kolmogorov-Smirnov Test: $p<0.001$ ). Trials comprised the following study arms: MAT $(n=655)$, IC $(n=570)$, computer-training group $(n=92)$, fitness intervention $(n=108)$, strength training $(n=104)$, balance training $(n=37)$, coordination training $(n=20)$, strength and 


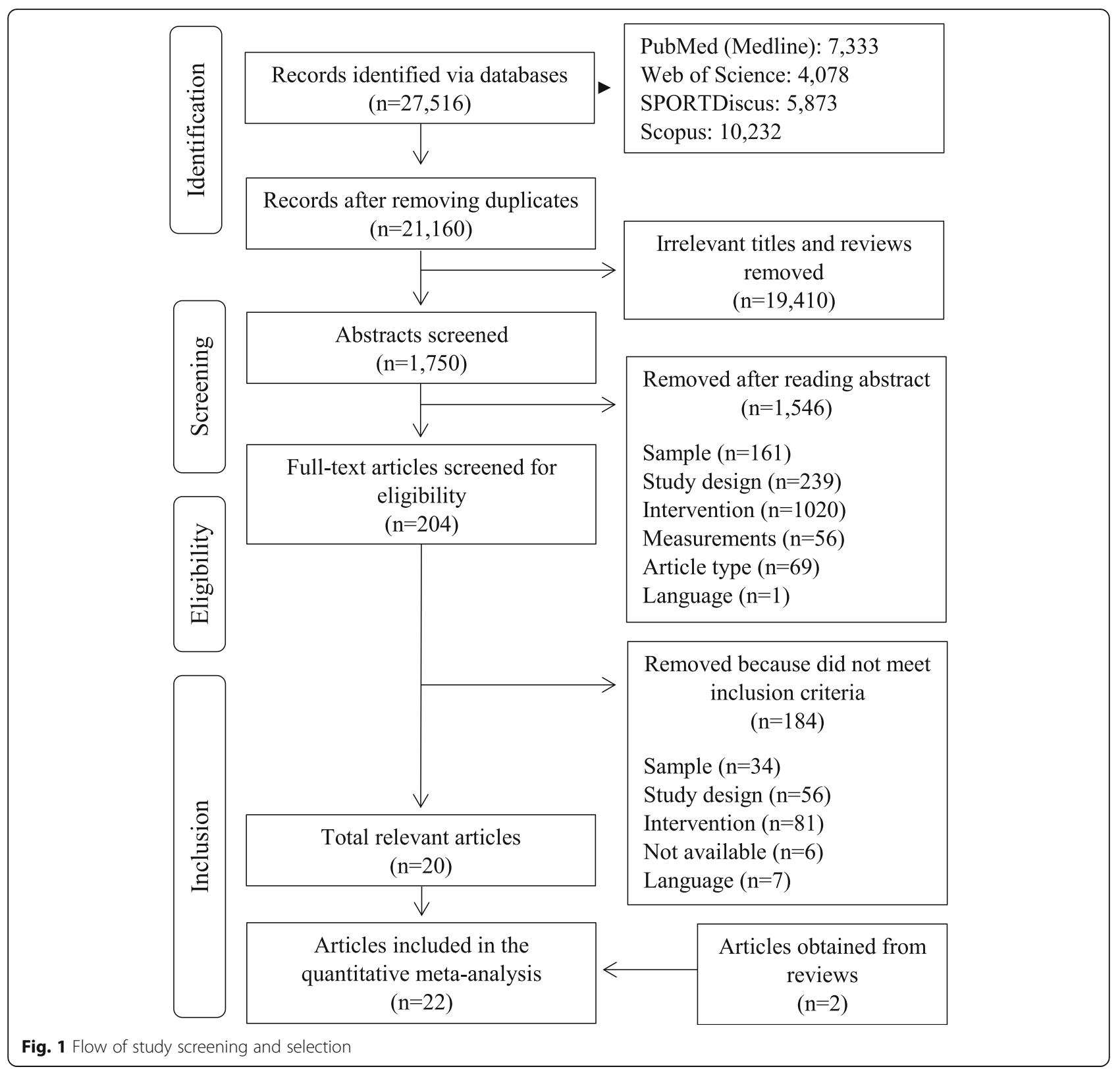

balance training $(n=19)$ and strength and endurance training $(n=16)$. Thus, exercise control groups comprised 247 participants as described in the methods section. Accordingly, 1472 participants $(655+570+247$; $90 \%$ ) were finally included into the meta-analysis.

Fifteen out of 20 studies used a two-armed [14, 16, 17, $19,31,34-40,42-44]$, three studies a three-armed [18, $29,40,41]$ and two studies a four-armed study design $[13,15]$. As it was part of the inclusion criteria, all studies applied standard randomization procedures for group assignment. According to the PEDro score, the median of the study quality was 6 and ranged from 4 [31, 37, 43] to $8[17,18,35]$ (see Table 3 ). None of the studies blinded participants or therapists, since blinding is problematic within exercise intervention studies. Nine of the 20 included studies blinded the assessors [15, 17-19, $34-36,41,44]$. Only two did not specifically report participant eligibility [18, 37].

Although only four studies included cognitive measures, the outcome domains varied strongly (e.g. orientation, memory, language, attention, executive function, inhibition and more). Since an analysis in which all domains would be pooled would be too heterogeneous, it was decided to leave out cognition in further analyses.

\section{Risk of bias assessment}

Funnel plots for all outcomes for the comparison of MAT vs. IC are shown in Fig. 2. They do not show a 


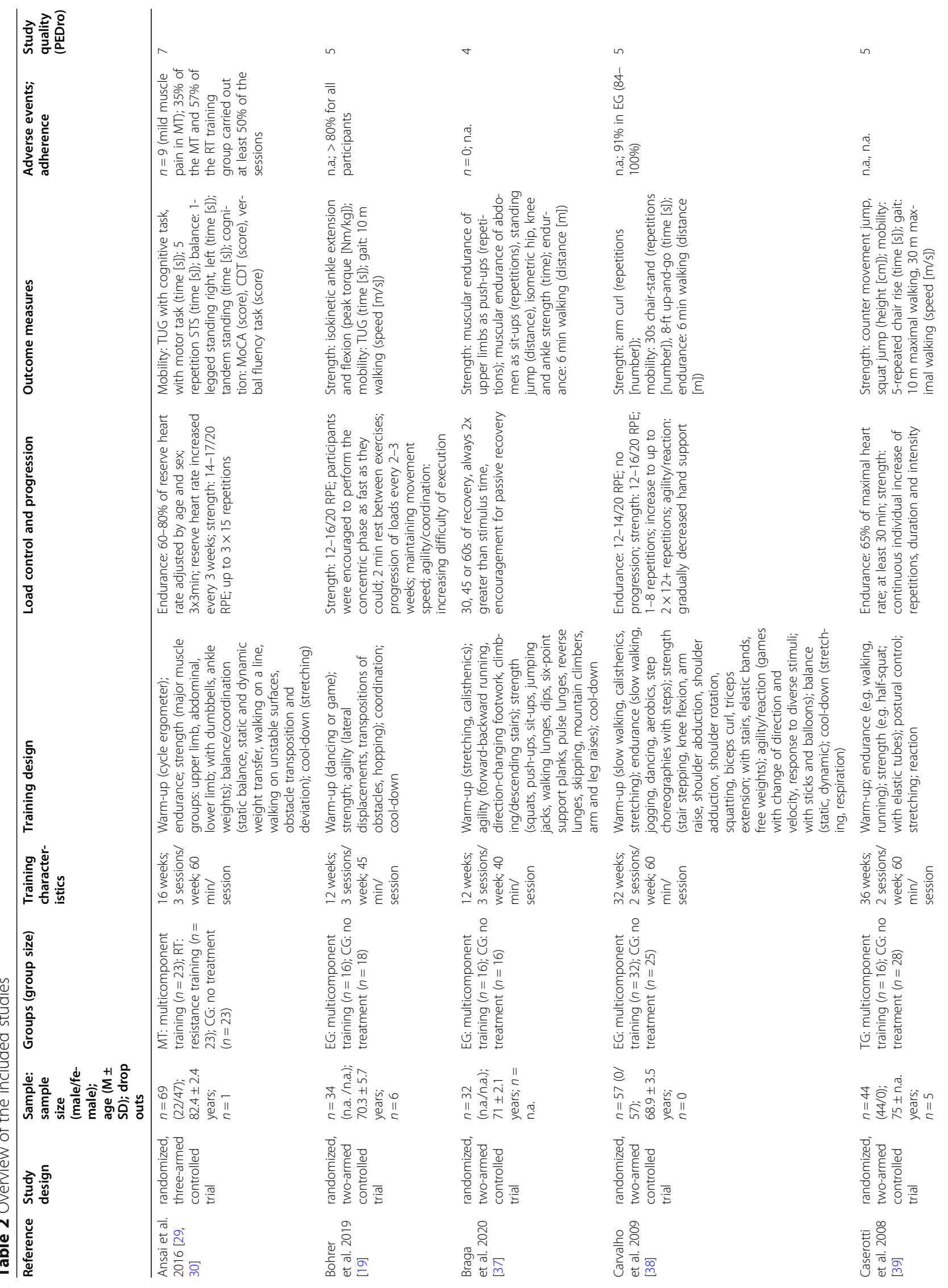




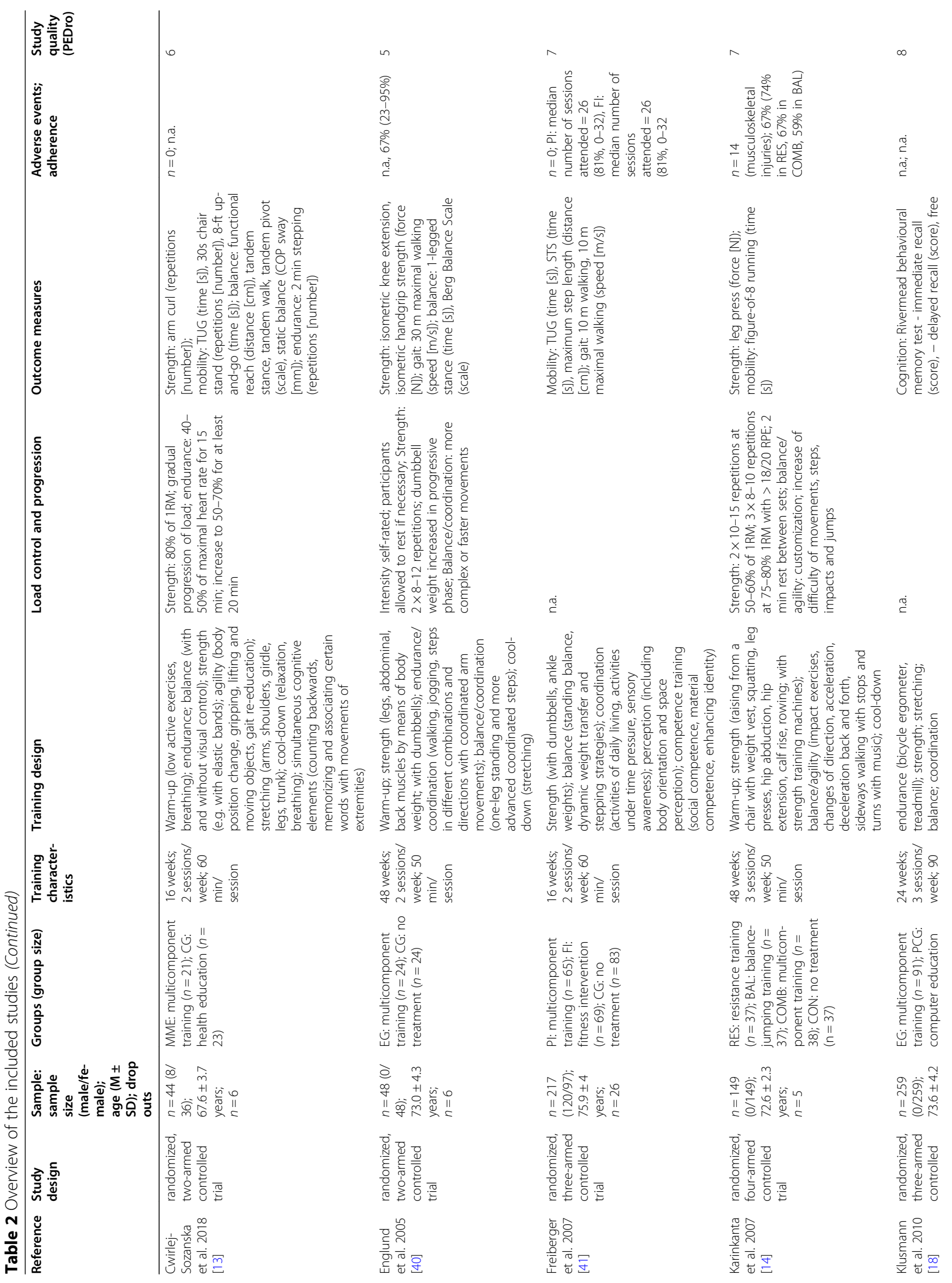




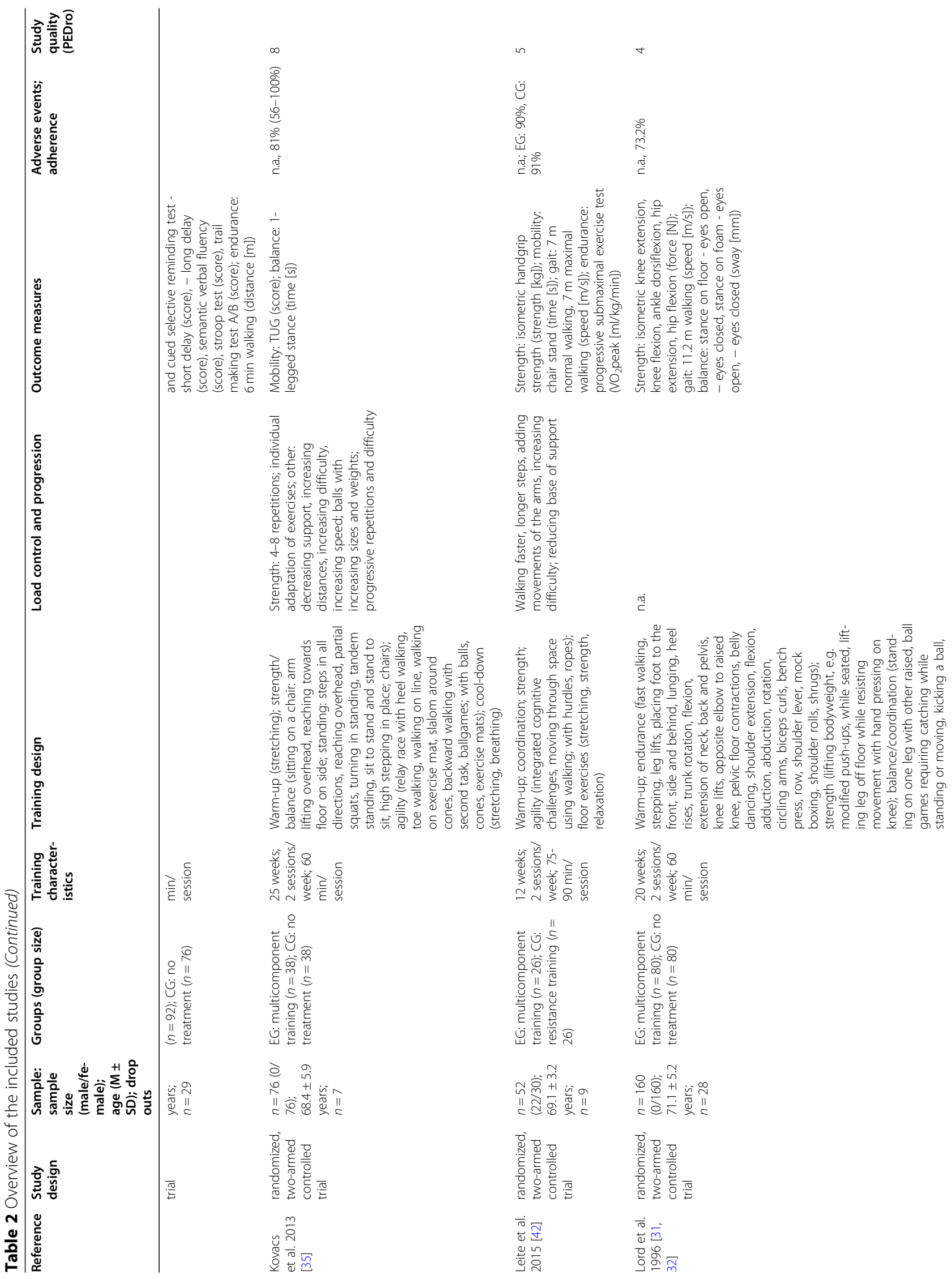




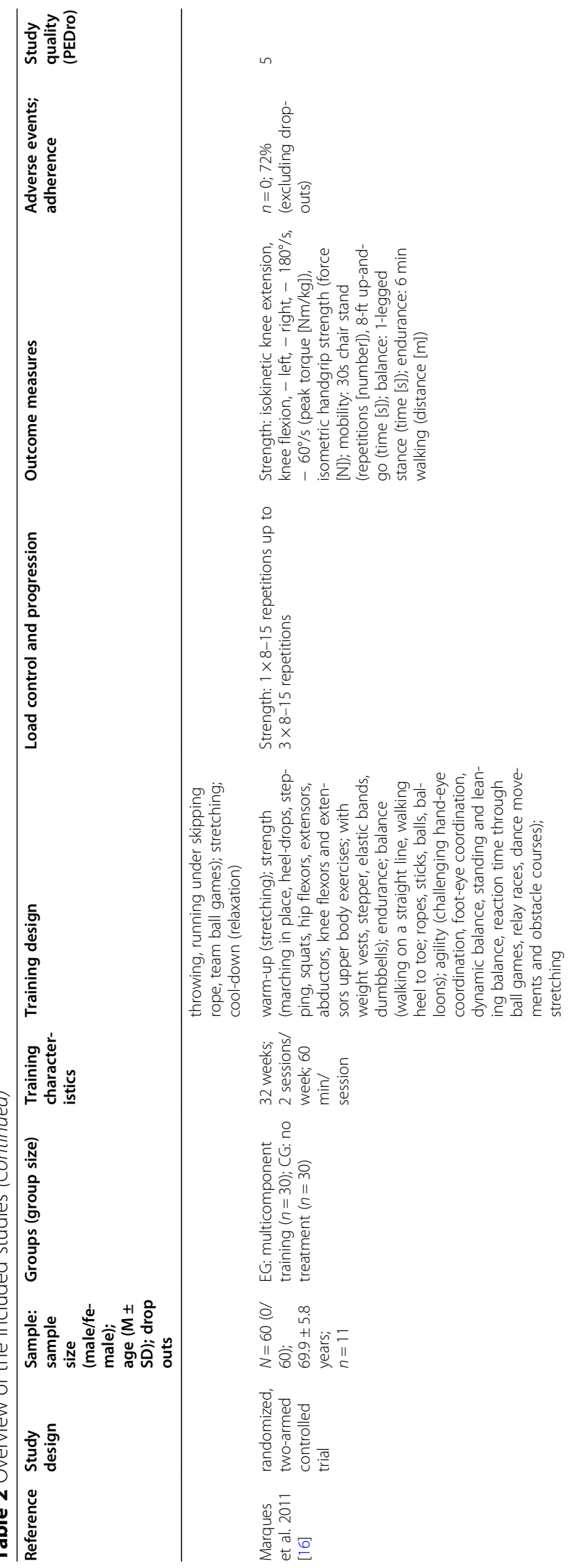

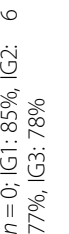

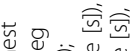

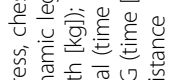

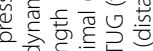

Ò

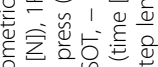

o d

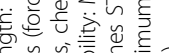

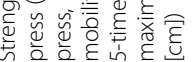

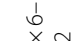

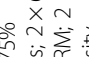

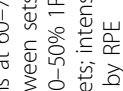

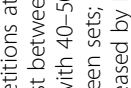

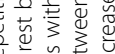

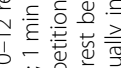

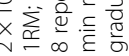

苞鱼 중 능 氜

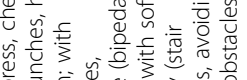

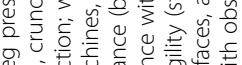

ه

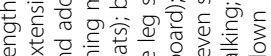

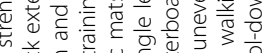

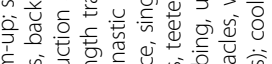

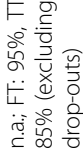

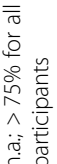

乞

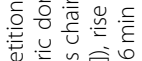

일

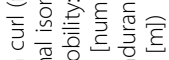

ह. है.

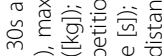

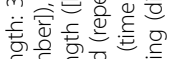

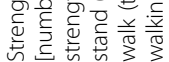

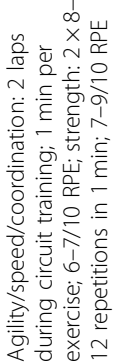

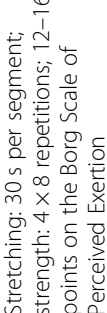

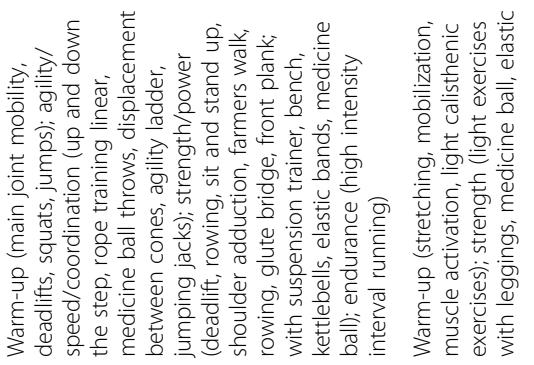

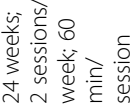

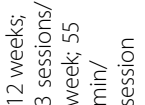

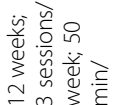

䒕 먼

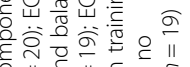

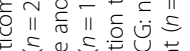

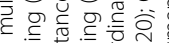

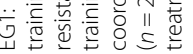

$\infty \stackrel{\substack{0 \\ 0}}{\infty}$

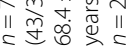

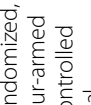

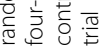

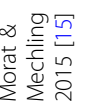

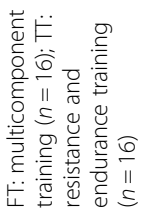

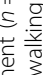

产 항.

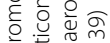

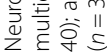

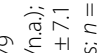

Iㅔㅇㅔ

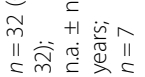

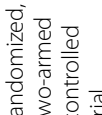

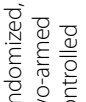

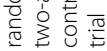

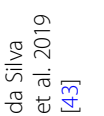




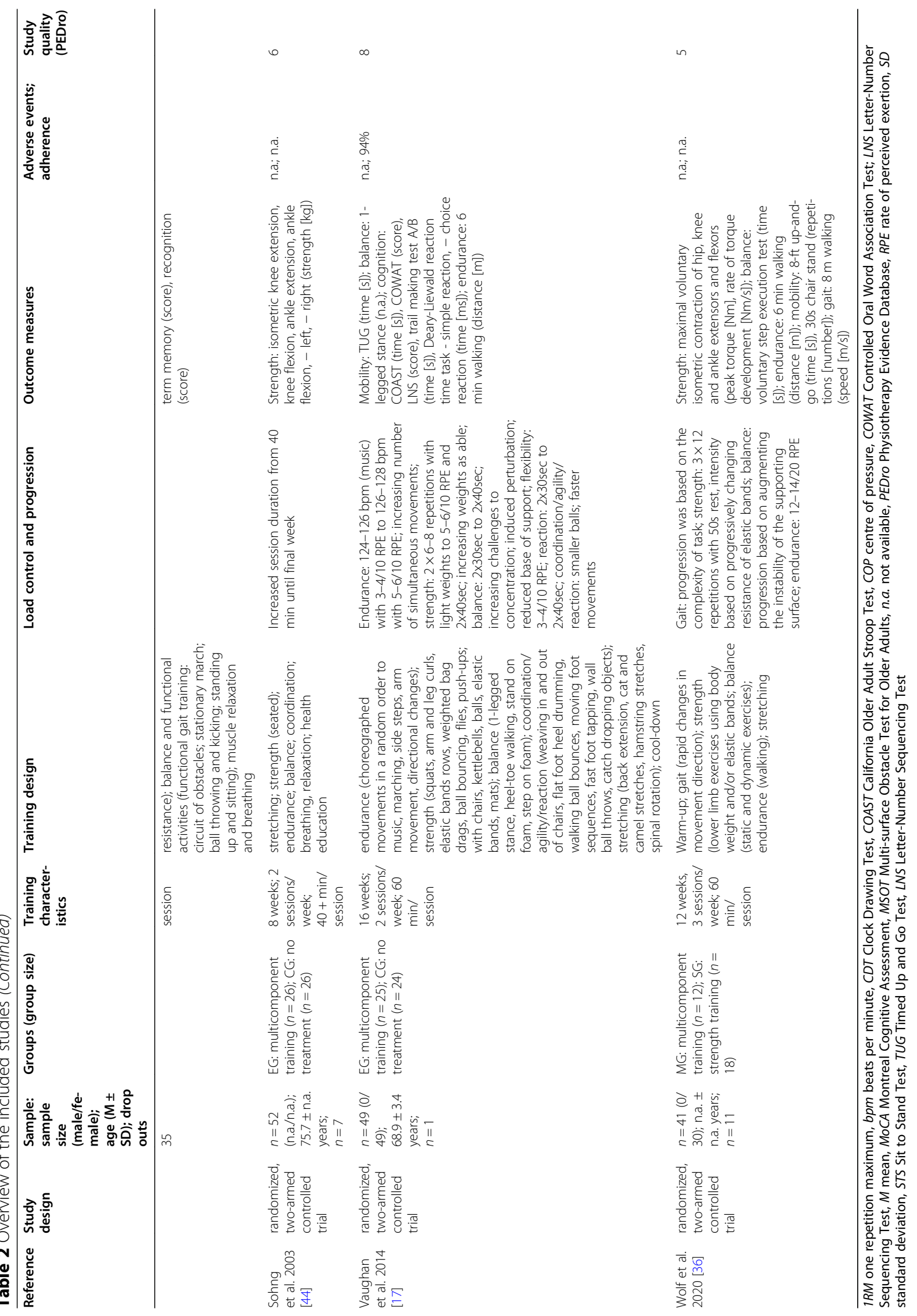




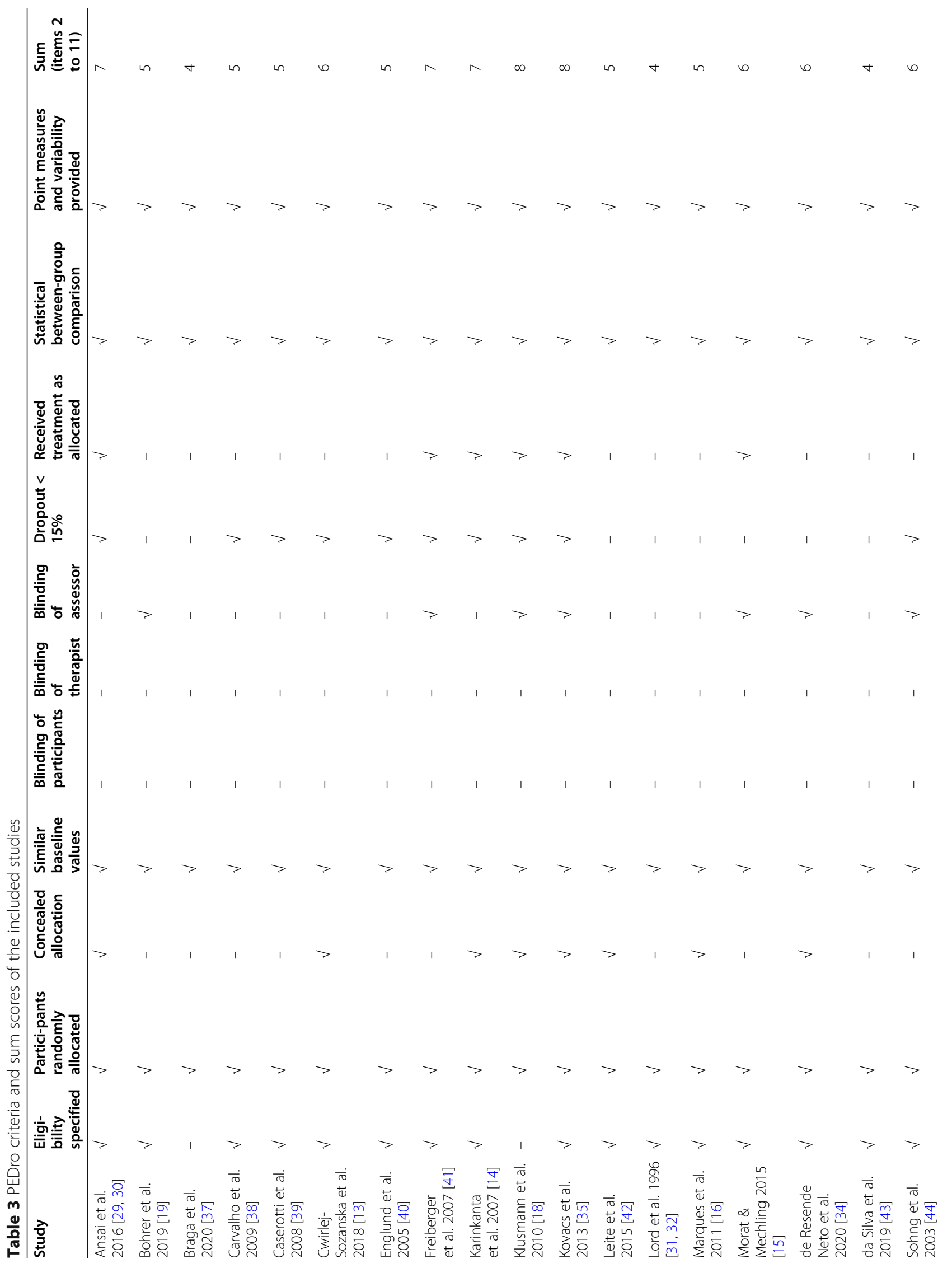




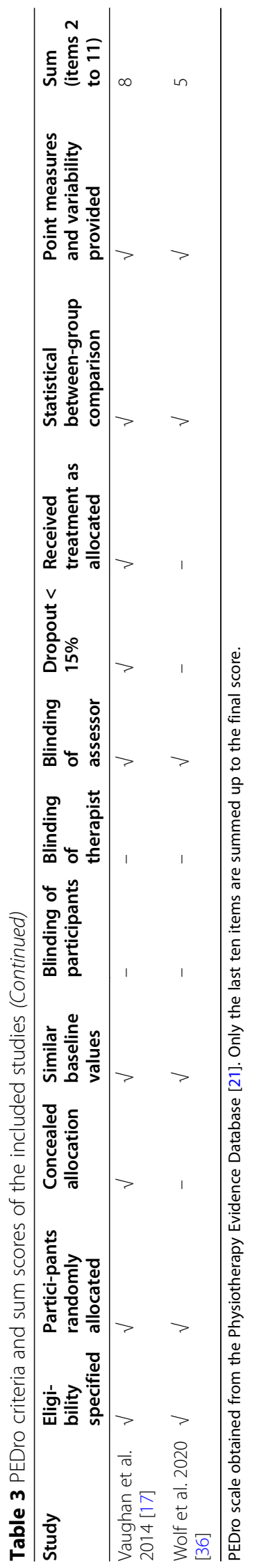



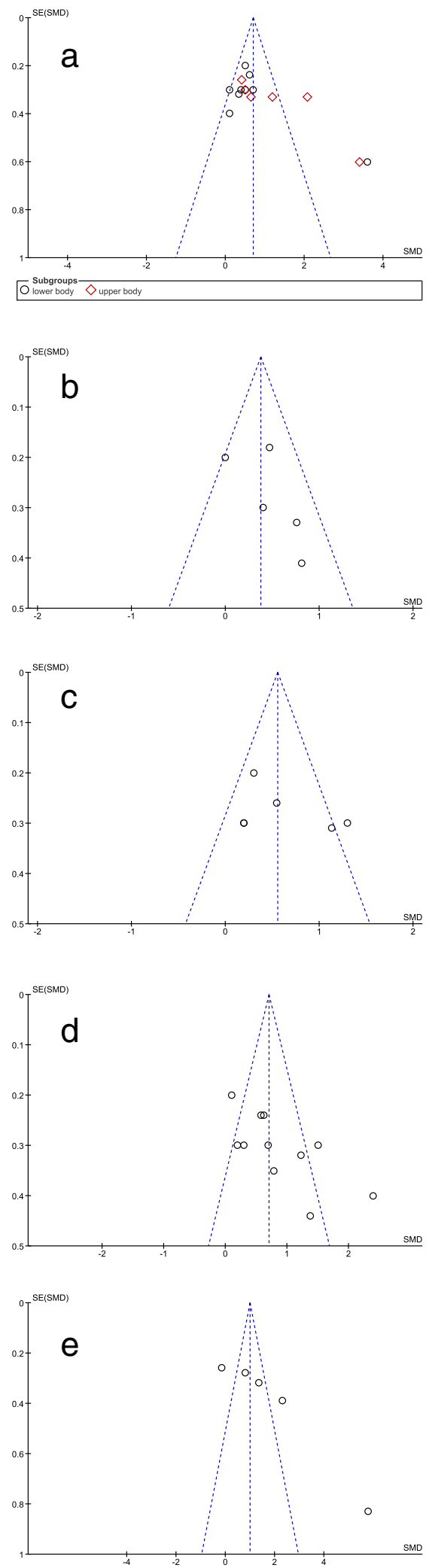

Fig. 2 Funnel plots for bias assessment MAT vs. IC: a overall strength; $\mathbf{b}$ gait; $\mathbf{c}$ balance; $\mathbf{d}$. mobility; e endurance. MAT = multimodal agility-like exercise training; $\mathrm{IC}=$ inactive control group; $\mathrm{SE}=$ standard error; $\mathrm{SMD}=$ standardized mean difference. The dashed line indicates the mean SMD

clear funnel-shape. This is also true for the separate plots of upper and lower body strength that are displayed together as overall strength. No studies with smaller sample sizes (higher standard errors) that usually scatter more widely at the bottom are present. The distribution of studies on the left and right side of the dashed standardized mean difference (SMD) line is equal for outcome measures of gait and balance, but not for strength, mobility and endurance.

Data analyses of MAT vs. IC

Small overall effects with very low heterogeneity were observed in favour of MAT for gait $(p=0.006$, SMD: 0.41 (90\% CI: 0.17, 0.65), $\mathrm{I}^{2}=0.36$ ). Lower body strength $(p=0.002$, SMD: 0.62 (90\% CI: $\left.0.3,0.95), \mathrm{I}^{2}=0.74\right)$ and balance $(p=0.001$, SMD: 0.6 (90\% CI: $0.29,0.9), \mathrm{I}^{2}=$ $0.64)$ showed moderate effects at moderate to high heterogeneity. Upper body strength $(p \leq 0.001$, SMD: 1.28 (90\% CI: $\left.0.67,1.88), \mathrm{I}^{2}=0.86\right)$, overall strength $(p<$ 0.001, SMD: 0.88 (90\% CI: 0.58, 1.19), $\mathrm{I}^{2}=0.81$ ), mobility $\left(p<0.001\right.$, SMD: 0.84 (90\% CI: 0.54, 1.15), $\left.\mathrm{I}^{2}=0.77\right)$ and endurance $(p=0.004$, SMD: 1.82 (90\% CI: $0.78,2.87)$, $\left.\mathrm{I}^{2}=0.94\right)$ revealed large overall effects at large heterogeneity. However, all effects were significantly in favour of MAT (see Figs. 3, 4, 5, 6 and 7).

\section{Data analyses of MAT vs. AC}

Few data were available for the comparison of effects of MAT vs. AC. No statistically significant effects were observed for any of the target outcome measures. Effects were mostly negligible, except for small effects on mobility and endurance in favour of MAT with large study heterogeneity (see Additional File 1 - Fig. S1 - Fig. S5): lower body strength (n (studies) $=4[13,15,34,36], p=$ 0.78, SMD: -0.05 (90\% CI: $-0.32,0.23), \mathrm{I}^{2}=0.11$ ), upper body strength (n (studies) $=3[15,34,42], p=0.83$, SMD: -0.04 (90\% CI: $\left.-0.36,0.27), \mathrm{I}^{2}=0.00\right)$, overall strength (n (studies) $=5[13,15,34,36,42], p=0.92$, SMD: -0.01 (90\% CI: $-0.21,0.19), \mathrm{I}^{2}=0.0$ ), gait (n (studies) $=3[36,41,42], p=0.92$, SMD: -0.02 (90\% CI: -0.34 , 0.39 ), $\mathrm{I}^{2}=0.46$ ), balance ( $\mathrm{n}$ (studies) $=2[29,36], p=$ 0.24, SMD: 0.41 (90\% CI: $-0.17,0.99), \mathrm{I}^{2}=0.52$ ), mobility (n (studies) $=7[13,15,29,34,36,41,42], p=0.09$, SMD: 0.25 (90\% CI: 0.01, 0.48), $\left.\mathrm{I}^{2}=0.41\right)$, endurance ( $\mathrm{n}$ (studies) $=3$ [34, 36, 42], $p=0.72$, SMD: 0.16 (90\% CI: $0.57,0.89), \mathrm{I}^{2}=0.76$ ). 


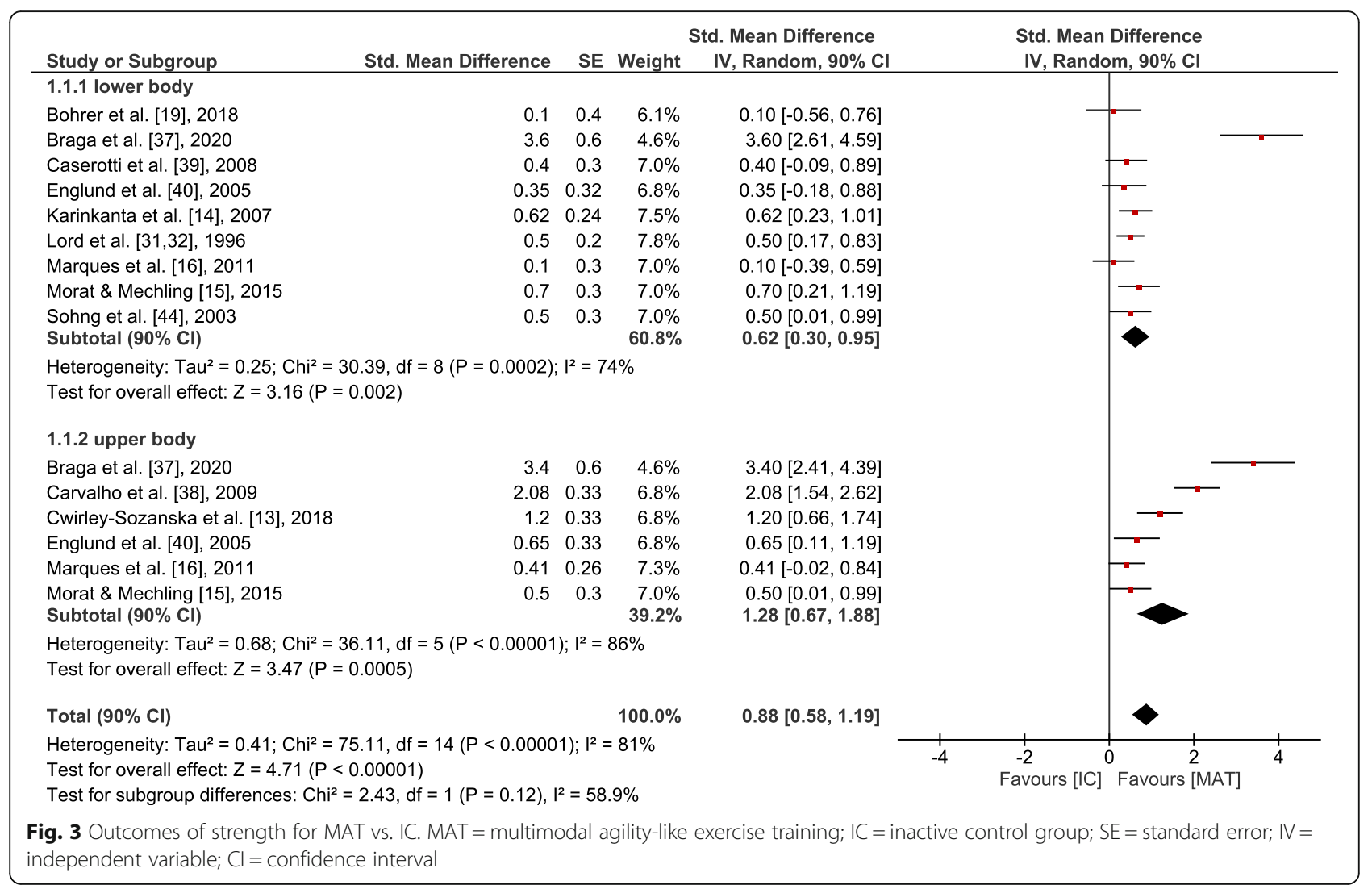

\section{Discussion}

To the best of our knowledge, no previously published meta-analytical review quantitatively evaluated the effects of multimodal agility-like exercise training (MAT) for community-dwelling older adults. The aim of this meta-analysis was to assess whether MAT provides superior effects compared to an inactive (IC) or alternative training control (AC) condition on physical and cognitive performance of older adults. According to the previously published agility framework by Donath et al. [12], we focus on multimodal agility-like training, where a combination of at least two traditional training domains (strength, balance, endurance) plus mandatory agilitylike exercises (coordination and change of direction and velocity) are required, even if different terminology is used, and investigated effects on physical and cognitive performance. We found interventions ranging from a minimum of three domains (e.g. strength, balance, agility inspired exercises [15]) to five domains (e.g. flexibility, agility inspired exercises, coordination, strength, endurance [34]) but all following the multimodal agility-like rational. In other reviews on multimodal training, the content of the MT interventions was manifold and heterogeneous sometimes without clear categorisation framework and inclusion/ exclusion criteria were partly lacking [45-48]. Only one meta-analysis considered and specifically named "agility" as a potential training domain [48]. The characteristics of the interventions in our

\begin{tabular}{|c|c|c|c|c|c|c|c|}
\hline Study or Subgroup & Std. Mean Difference & SE & Weight & $\begin{array}{l}\text { Std. Mean Difference } \\
\text { IV, Random, } 90 \% \mathrm{CI}\end{array}$ & $\begin{array}{l}\text { Std. Mean D } \\
\text { IV, Randon }\end{array}$ & $\begin{array}{l}\text { Difference } \\
\mathrm{m}, 90 \% \mathrm{Cl}\end{array}$ & \\
\hline Bohrer et al. [19], 2018 & 0.81 & 0.41 & $10.4 \%$ & $0.81[0.14,1.48]$ & & & \\
\hline Caserotti et al. [39], 2008 & 0.4 & 0.3 & $16.8 \%$ & $0.40[-0.09,0.89]$ & & & \\
\hline Englund et al. [40], 2005 & 0.76 & 0.33 & $14.7 \%$ & $0.76[0.22,1.30]$ & & & \\
\hline Freiberger et al. [41], 2007 & 0 & 0.2 & $27.6 \%$ & $0.00[-0.33,0.33]$ & & & \\
\hline Lord et al. [31,32], 1996 & 0.47 & 0.18 & $30.5 \%$ & $0.47[0.17,0.77]$ & & & \\
\hline Total $(90 \% \mathrm{Cl})$ & & & $100.0 \%$ & $0.41[0.17,0.65]$ & & & \\
\hline \multicolumn{4}{|c|}{$\begin{array}{l}\text { Heterogeneity: } \mathrm{Tau}^{2}=0.04 ; \mathrm{Chi}^{2}=6.29, \mathrm{df}=4(P=0.18) ; \mathrm{I}^{2}=36 \% \\
\text { Test for overall effect: } Z=2.77(P=0.006)\end{array}$} & -2 & $\begin{array}{l}-1 \\
\text { Favours }[I C]\end{array}$ & Favours [MAT] & 2 \\
\hline
\end{tabular}




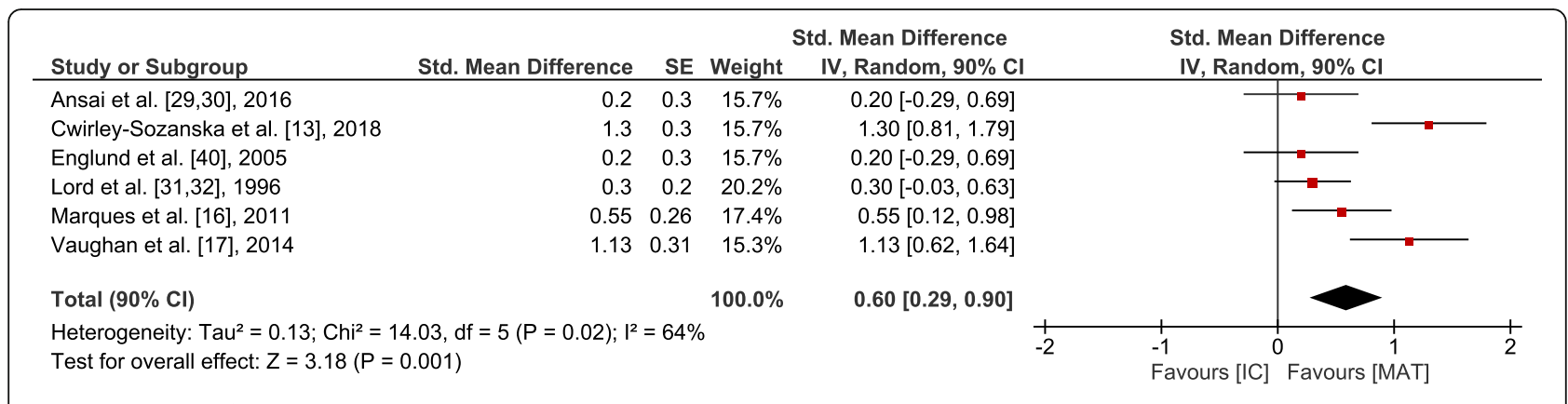

Fig. 5 Outcomes of balance for MAT vs. IC. MAT= multimodal agility-like exercise training; IC = inactive control group; $S E=s t a n d a r d ~ e r r o r ; ~ I V=$ independent variable; $\mathrm{Cl}$ = confidence interval

meta-analysis varied considerably with intervention durations ranging from 8 to 48 weeks (mean: $21.7 \pm 11.9$ weeks), two to three sessions per week (mean: $24.4 \pm$ 0.5 total sessions) and a session duration of 40 to $90 \mathrm{~min}$ (mean: $58 \pm 11.6 \mathrm{~min}$ ), which is consistent with other analyses on MT [47]. Study samples in our meta-analysis were homogenous due to inclusion and exclusion criteria with most studies including participants with a mean age between 67 and 75 years. Only small sample sizes were missing, revealing a potential risk of bias. Outcome measures were manifold, like in other metaanalyses on MT [45-47] and were therefore grouped as strength, gait, balance, mobility, endurance and cognition. Within each domain, different target outcomes were pooled, which were mostly homogenous, except for strength outcomes with a variety of tests.

We found notable effects in favour of MAT compared to IC in all examined measures of physical performance. The largest effects in favour of MAT compared to IC were observed for measures of upper body strength, mobility and endurance. When comparing the effects of MAT vs. AC, effects were all insignificant and effect sizes were mostly negligible for physical performance.
With large heterogeneity and few study comparison, small effects in favour of MAT compared to AC were observed for balance and mobility.

\section{Effects on strength}

Effects of MAT on overall strength compared to an IC were large with moderate effects on lower body strength and large effects on upper body strength. In most of all included studies, strength training within MAT implied whole-body training with body weight or small devices (e.g. elastic bands, dumbbells). In all studies that examined the effects on strength in comparison to an $\mathrm{AC}$, control groups had a focus on strength training. Still, $\mathrm{AC}$ and MAT did reveal similar effects on strength, whereas MAT is more likely to additionally induce improvements in other physical domains. For lower and upper body strength, the lowest effect sizes were observed for studies with limited study quality $[16,19]$. Outcome measures of upper body strength were heterogeneous: studies that applied push-ups or arm curls revealed extremely large effect sizes [14, 37, 38], whereas moderate effect sizes were found in studies measuring isometric grip strength $[38,40]$ and isometric and

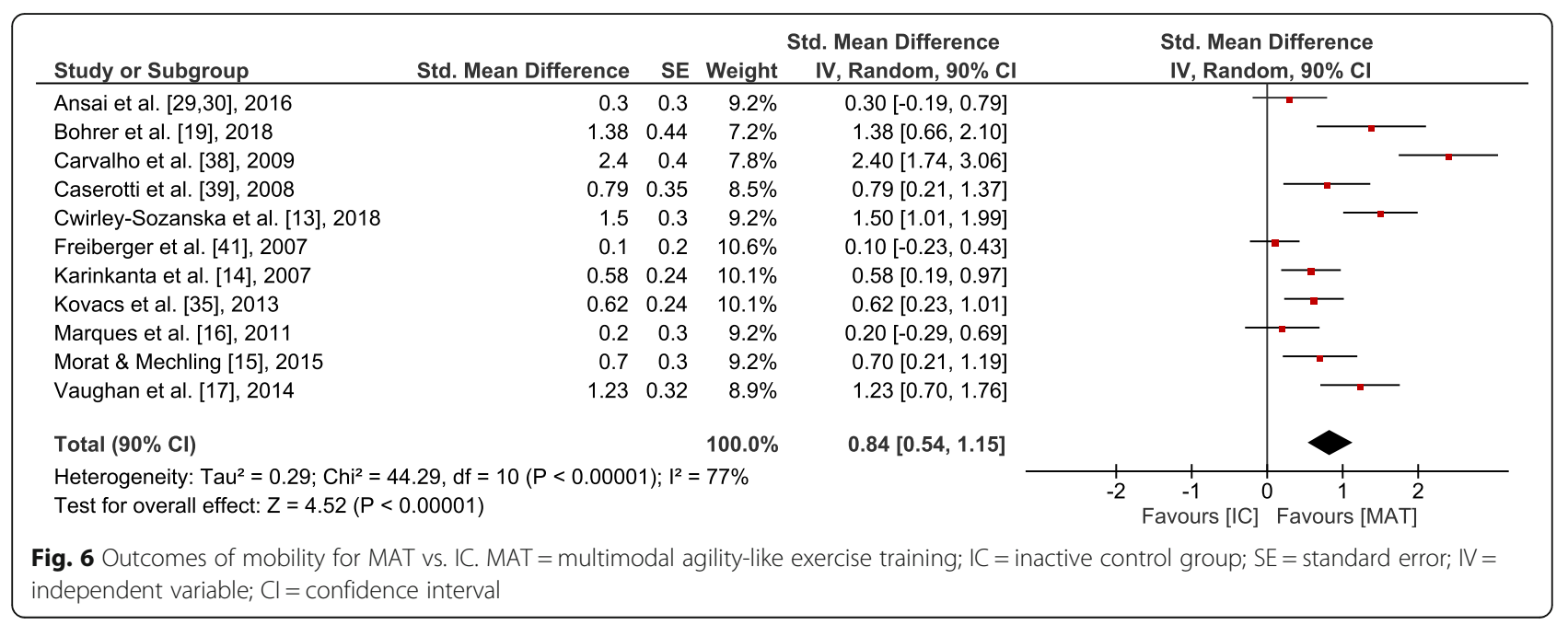




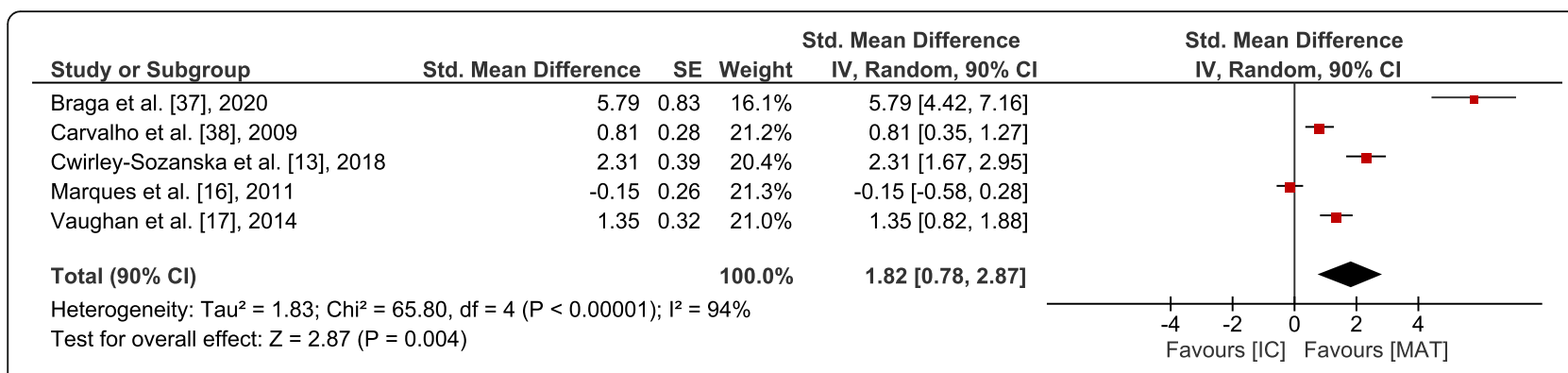

Fig. 7 Outcomes of endurance for MAT vs. IC. MAT = multimodal agility-like exercise training; IC = inactive control group; $S E=s t a n d a r d ~ e r r o r ; ~ I V=$ independent variable; $\mathrm{Cl}=$ confidence interval

dynamic chest press [15]. Higher effects on upper body strength compared to lower body strength might be due to higher similarities of testing and training.

Falck et al. [45] reviewed 48 studies of diverse exercise training regimen in older adults aged 60 years and also recommend MT for the improvement of strength performance. In 2004, Moreland et al. [49] claimed that muscle strength is a main aspect of fall prevention. Additionally, Granacher et al. [50] stated in their review that the effects of most strength training programs that are focusing on lower extremities are poorly translated into positive effects on balance, functional tasks, activities of daily living (ADL) and fall rates. Strength training as part of integrative MAT seems promising in terms of improvements of upper and lower body strength and may account for these translations.

\section{Effects on gait}

As walking was included in MAT concepts of all but one studies [41], measures of gait showed effects in favour of MAT compared to an IC. Altogether, the included studies were relatively homogenous $\left(\mathrm{I}^{2}=0.36\right)$ with similar underlying testing procedures. MAT is likely to improve habitual, as well as maximum gait speed. Mortaza et al. [51] showed that older adults who are categorized as fallers have a tendency towards slower gait speed and lower cadence, longer stride time and longer double support time. Regarding effects on different aspects of gait, the selection of suitable and sensitive gait analysis and target measures is decisive to assess effects of training programs on fall relevant aspects of gait. For the comparison to an AC, three studies showed no difference of effects on gait between groups.

\section{Effects on balance}

Six studies with a moderately large heterogeneity $\left(\mathrm{I}^{2}=\right.$ 0.64) were included in the analysis of effects on balance performance for MAT compared to IC with moderate effects in favour of MAT. Only two studies included balance measures with a comparison to an AC leaving insufficient data for analysis. All studies within the comparison to IC employed static balance conditions in testing and performed balance training in MAT as a combination of static and dynamic exercises in training. MAT might have even larger effects on dynamic balance that were only assessed in one of the included studies. Only Cwirlej-Sozanska et at [13]. also included functional outcomes (functional reach, tandem walk, tandem pivot). Since MAT emphasizes dynamic balance tasks, such as agility and coordination, this more functional testing approach might account for larger effects in this study, according to the task-specificity principle of neuromuscular training adaptations, which is especially relevant for balance training [4]. Functional balance, allowing for movement patterns in time and space without losing balance, are crucial for older adults' daily activities and thus should be part of MAT [12]. With its variety of training domains, MAT can easily include dynamic and functional balance demands in a specific balance tasks or embedded in agility tasks. Vaughan et al. [17], who reported the second highest effect size in favour of MAT compared to IC, were among the few studies that reported progression of balance training.

\section{Effects on mobility}

Large effects were observed for mobility outcomes in favour of MAT compared to an IC. There were relevant but small effects in comparison to an $\mathrm{AC}$ in favour of MAT but without statistical significance. Since the terminology "agility" for older adults is neither established nor used much in literature, "agility" was comprehensively understood as coordination and change of direction and velocity in our meta-analysis. Thus, exercises for agility, also addressing mobility outcomes, were present in all studies but appeared differently. The most frequently used mobility measure was the TUG and the STS test. Carvalho et al. [38] revealed extremely large effects of MAT on mobility compared to IC. It strikes out that their MAT design incorporated some aspects of the original agility concept by Donath et al. [12] as they included at least one of the following criteria: change of direction, change of velocity (start stop), balance (static 
and dynamic), strength and endurance in MAT in different forms and not always all aspects of agility.

Among the studies with the highest SMD for mobility were two that simultaneously revealed the highest effects on balance outcomes [14, 17] and on gait [19]. Dynamic aspects of balance and improvements in gait might show transfer effects on mobility measures like the Timed Up and Go Test for older adults, where participants must walk and turn, maintaining an upright posture. However, a relatively high methodological heterogeneity of studies makes it hard to draw a further conclusion. The same is true for the comparison of effects of MAT on mobility compared to an AC. Small but insignificant effects tend to show that MAT is a better means to improve mobility and therefore functional abilities in older adults as compared to resistance training alone or combined with one additional training domain only. MAT should imply agility-specific exercises involving changes of direction and velocity, balance, strength, and endurance components, following the agility approach by Donath et al. [12]. This seems particularly promising for everyday life activities for older adults in which they also must turn, accelerate, decelerate, and stand without losing balance and without fatiguing. Other meta-analyses, investigating effects of MT also report greater effects of MT on mobility outcomes compared to IC as well as AC [45-47]. However, the perceptual aspects of agility training and the characteristics of an original definition by Sheppard and Young [52]: "a rapid whole-body movement with change of velocity or direction in response to a stimulus", comprising a perceptual decision-making process and its outcome, a change of direction or velocity task is often missing in recent studies. A recently published pilot study [53] specifically included agility-based exercises being based upon the agility approach by Donath et al. [12]. In addition, Morat et al. [54] published the protocol of their planned RCT evaluating agility training for older adults.

\section{Effects on endurance}

Despite a high heterogeneity of studies, the effects of MAT on endurance were large compared to IC. All but one studies on endurance performance included a specific endurance exercises domain within MAT, whereas a detailed training prescription was only provided in few studies. All except one study applied the 6 min walking test as an outcome measure for endurance. CwirleySozanska et al. [13] performed the 2 min step test revealing large effects. The 2 min step test appears to benefit from other physical domains like strength and balance besides endurance exercises and agility-specific tasks might additionally address more anaerobic endurance. Marques et al. [16] showed negligible effects in favour of IC $(S M D=-0.15)$ although they included exercises like marching, stepping, ball games and relay races in MAT that seem to beneficially affect endurance. A more anaerobe endurance test (like the 2 min step test) might have led to different results. Effects of MAT on endurance performance can be expected by integrating classical endurance components, but also by planning and progressing other training domains like agility or coordination in a way that a cardiovascular stimulus is induced. This is in line with results of a meta-analysis that reviewed effects of MT in older populations compared to IC and AC and revealed greater effects on peak oxygen consumption of MT compared to an endurance training AC and IC [46].

\section{Effects on cognition}

As it was previously described, cognition was left out of any further analysis due to the heterogeneity of outcome domains within the four relevant studies. But it seems worth investigating, if adding cognitive demands to MAT exercises would enlarge effects on cognitive performance measures [22].

\section{Limitations}

This meta-analysis is the first that evaluates the effects of MAT in older adults with pooled effect sizes for the comparison to $\mathrm{AC}$ and $\mathrm{IC}$ and was reported according to the PRISMA guidelines [20]. One limitation that needs to be mentioned is that risk of bias assessment indicated potential bias from missing studies with small sample sizes. Also, due to a lack of studies including similar testing procedures, pooling of several testing procedures for some outcome measures was performed which compromises the significance of findings. Study heterogeneity varied between $\mathrm{I}^{2}=0.0$ and $\mathrm{I}^{2}=0.94$ between outcome measures. Despite noteworthy heterogeneity concerning sample sizes, intervention duration and study arms, the findings offer a unique comprehensive qualitative view on recent scientific evidence on the effects of multimodal agility-like exercise interventions with a convenient pool of data. Effects of MAT vs. AC might be more biased because of the heterogeneity of control conditions. Additionally, the low number of studies that included AC requires more studies with multiple study arms and high study quality. Within our meta-analysis, no specific health and fall prevention outcomes have been considered, however, they could indirectly benefit from agility exercises.

\section{Conclusions}

Multimodal agility-like exercise training (MAT) can improve different physical performance aspects relevant for healthy and successful aging of older adults. The effects were comparable to those of alternative exercise training regimen. Thus, this meta-analysis showed that MAT 
might offer a time-efficient training option for older adults, since positive effects in many measures of physical performance can be achieved with a training volume that traditionally just allows for the training of one or two physical domains. Studies partly include selective aspects of MAT but lack clear definitions or categorization towards the agility framework by Donath et al. [12]. According to this framework, exercises comprising changes of direction and velocity, as well as exercises for improving balance, strength and endurance are essential to train relevant abilities for everyday life activities of older adults. Comprehensive multimodal agility training concepts bring the advantage of reproducing real-life conditions and therefor offer more opportunity for transfer; however, this must be investigated more. With this in mind, the results of a first pilot-study [53] are promising and the evaluation of an innovative agility training approach within an RCT study [54] could provide further insights about the effects of agility training in older adults. Thus, the present meta-analysis highlights the importance of MAT for older adults and provides important insights for future training conceptualization. The systematic application of exercise science principles and load control during agility training in long-term intervention studies is required.

\section{Supplementary Information}

The online version contains supplementary material available at https://doi. org/10.1186/s11556-021-00256-y.

Additional file 1.

\section{Abbreviations}

AC: Active controls; ADL: Activities of daily living; Cl: Confidence intervals; IC: Inactive controls; MAT: Multimodal agility-like exercise training; MT: Multimodal exercise training; PED: Physiotherapy Evidence Database; RCT: Randomized controlled trial; SMD: Standardized mean differences; STS: Sit to Stand Test; TUG: Timed Up and Go Test

\section{Acknowledgements}

Not applicable.

\section{Authors' contributions}

MM, TM and LD designed the study. MM performed a systematic search of the literature. MM and TM performed the selection of studies and evaluated the methodological quality of all studies. MM and TM extracted data of the included studies. MM, TM, LD and WZ wrote the original draft. MM, TM, LD and $W Z$ reviewed and revised the manuscript. LD supervised the whole process. All authors read and approved the final manuscript.

\section{Authors' information}

Not applicable.

\section{Funding}

No financial or material support was given. Open Access funding enabled and organized by Projekt DEAL.

\section{Availability of data and materials}

Data sharing is not applicable to this meta-analysis as no datasets were generated or analysed. All data generated or analysed are included in this published article [and its supplementary information files].
Ethics approval and consent to participate

Not applicable.

\section{Consent for publication}

Not applicable.

\section{Competing interests}

The authors have no competing interests to declare.

\section{Author details}

${ }^{1}$ Institute of Exercise Training and Sport Informatics, Department of Intervention Research in Exercise Training, German Sport University Cologne, Am Sportpark Muengersdorf 6, 50933 Cologne, Germany. ${ }^{2}$ Institute of Movement and Sport Gerontology, German Sport University Cologne, Am Sportpark Muengersdorf 6, 50933 Cologne, Germany.

Received: 15 October 2020 Accepted: 26 January 2021

Published online: 25 February 2021

\section{References}

1. Lutz W, Sanderson W, Scherbov S. The coming acceleration of global population ageing. Nature. 2008;451:716-9. https://doi.org/10.1038/ nature06516.

2. Dziechciaż M, Filip R. Biological psychological and social determinants of old age: bio-psycho-social aspects of human aging. Ann Agric Environ Med. 2014;21:835-8. https://doi.org/10.5604/12321966.1129943.

3. McPhee JS, French DP, Jackson D, Nazroo J, Pendleton N, Degens $H$. Physical activity in older age: perspectives for healthy ageing and frailty. Biogerontology. 2016;17:567-80. https://doi.org/10.1007/s10522-016-9641-0.

4. Giboin L-S, Gruber M, Kramer A. Task-specificity of balance training. Hum Mov Sci. 2015;44:22-31. https://doi.org/10.1016/j.humov.2015.08.012.

5. Kuemmel J, Kramer A, Giboin L-S, Gruber M. Specificity of balance training in healthy individuals: a systematic review and meta-analysis. Sports Med. 2016;46:1261-71. https://doi.org/10.1007/s40279-016-0515-z.

6. Freyler K, Krause A, Gollhofer A, Ritzmann R. Specific stimuli induce specific adaptations: sensorimotor training vs. reactive balance training. PLoS One. 2016;11:e0167557. https://doi.org/10.1371/journal.pone.0167557.

7. Chodzko-Zajko WJ, Proctor DN, Fiatarone Singh MA, Minson CT, Nigg CR, Salem GJ, Skinner JS. American College of Sports Medicine position stand. Exercise and physical activity for older adults. Med Sci Sports Exerc. 2009;41: 1510-30. https://doi.org/10.1249/MSS.0b013e3181a0c95c.

8. WHO (World Health Organization). WHO guidelines on physical activity and sedentary behaviour. Geneva: World Health Organization; 2020.

9. Sherrington C, Fairhall NJ, Wallbank GK, Tiedemann A, Michaleff ZA, Howard $\mathrm{K}$, et al. Exercise for preventing falls in older people living in the community. Cochrane Database Syst Rev. 2019;1:CD012424. https://doi.org/ 10.1002/14651858.CD012424.pub2.

10. Lamb SE, Becker C, Gillespie LD, Smith JL, Finnegan S, Potter R, Pfeiffer K. Reporting of complex interventions in clinical trials: development of a taxonomy to classify and describe fall-prevention interventions. Trials. 2011; 12:125. https://doi.org/10.1186/1745-6215-12-125.

11. Kohler A, Kressig RW, Schindler C, Granacher U. Adherence rates in intervention programmes to promote physical activity among older people: A systematic literature review [Adhaerenz-Raten bei Interventionsprogrammen zur Bewegungsfoerderung aelterer Menschen: Ein systematischer Literaturueberblick]. Praxis (Bern 1994). 2012;101:1535-47. https://doi.org/10.1024/1661-8157/a001129.

12. Donath $L$, van Dieën J, Faude O. Exercise-based fall prevention in the elderly: what about agility? Sports Med. 2016;46:143-9. https://doi.org/10. 1007/s40279-015-0389-5

13. Ćwirlej-Sozańska A, Wiśniowska-Szurlej A, Wilmowska-Pietruszyńska A, Drużbicki M, Sozański B, Wołoszyn N, Guzik A. Evaluation of the effect of 16 weeks of multifactorial exercises on the functional fitness and postural stability of a low-income elderly population. Topics Geriatr Rehabil. 2018;34: 251-61. https://doi.org/10.1097/TGR.0000000000000202.

14. Karinkanta S, Heinonen A, Sievaenen H, Uusi-Rasi K, Pasanen M, Ojala K, et al. A multi-component exercise regimen to prevent functional decline and bone fragility in home-dwelling elderly women: randomized, controlled trial. Osteoporos Int. 2007;18:453-62. https://doi. org/10.1007/s00198-006-0256-1. 
15. Morat $\mathrm{T}$, Mechling $\mathrm{H}$. Training in the functional movement circle to promote strength and mobility-related activities in older adults: a randomized controlled trial. Eur J Ageing. 2015;12:105-18. https://doi.org/10. 1007/s10433-014-0325-9.

16. Marques NR, Spinoso DH, Cardoso BC, Moreno VC, Kuroda MH, Navega MT. Is it possible to predict falls in older adults using gait kinematics? Clin Biomech. 2018;59:15-8. https://doi.org/10.1016/j.clinbiomech.2018.08.006.

17. Vaughan S, Wallis M, Polit D, Steele M, Shum D, Morris N. The effects of multimodal exercise on cognitive and physical functioning and brainderived neurotrophic factor in older women: a randomised controlled trial. Age Ageing. 2014;43:623-9. https://doi.org/10.1093/ageing/afu010.

18. Klusmann V, Evers A, Schwarzer R, Schlattmann P, Reischies FM, Heuser I, Dimeo FC. Complex mental and physical activity in older women and cognitive performance: a 6-month randomized controlled trial. J Gerontol A Biol Sci Med Sci. 2010;65:680-8. https://doi.org/10.1093/ gerona/glq053.

19. Bohrer RCD, Pereira G, Beck JK, Lodovico A, Rodacki ALF. Multicomponent training program with high-speed movement execution of ankle muscles reduces risk of falls in older adults. Rejuvenation Res. 2019;22:43-50. https:// doi.org/10.1089/rej.2018.2063.

20. Hutton B, Salanti G, Caldwell DM, Chaimani A, Schmid CH, Cameron C, et al. The PRISMA extension statement for reporting of systematic reviews incorporating network meta-analyses of health care interventions: checklist and explanations. Ann Intern Med. 2015;162:777-84. https://doi.org/10.7326/ M14-2385.

21. Maher CG, Sherrington C, Herbert RD, Moseley AM, Elkins M. Reliability of the PEDro scale for rating quality of randomized controlled trials. Phys Ther. 2003:83:713-21

22. Bruderer-Hofstetter M, Rausch-Osthoff A-K, Meichtry A, Muenzer T, Niedermann K. Effective multicomponent interventions in comparison to active control and no interventions on physical capacity, cognitive function and instrumental activities of daily living in elderly people with and without mild impaired cognition - a systematic review and network meta-analysis. Ageing Res Rev. 2018;45:1-14. https://doi.org/10.1016/j.arr.2018.04.002.

23. Lord SR, Murray SM, Chapman K, Munro B, Tiedemann A. Sit-to-stand performance depends on sensation, speed, balance, and psychological status in addition to strength in older people. J Gerontol A Biol Sci Med Sci. 2002;57:M539-43. https://doi.org/10.1093/gerona/57.8.M539.

24. Deeks JJ, Higgins, Julian PT. Statistical algorithms in review manager 5. 2010. https://training.cochrane.org/hand. Accessed 25 Nov 2019.

25. Borenstein M, Hedges LV, Higgins JPT, Rothstein HR. A basic introduction to fixed-effect and random-effects models for meta-analysis. Res Synth Methods. 2010;1:97-111. https://doi.org/10.1002/jrsm.12.

26. Cohen J. Statistical power analysis for the behavioral sciences. 2nd ed. New York: Routledge; 1988

27. Higgins JPT, Thompson SG. Quantifying heterogeneity in a meta-analysis. Stat Med. 2002;21:1539-58. https://doi.org/10.1002/sim.1186.

28. Mueller KF, Meerpohl JJ, Briel M, Antes G, von Elm E, Lang B, et al. Methods for detecting, quantifying, and adjusting for dissemination bias in metaanalysis are described. J Clin Epidemiol. 2016;80:25-33. https://doi.org/10. 1016/j.jclinepi.2016.04.015.

29. Ansai JH, Aurichio TR, Gonçalves R, Rebelatto JR. Effects of two physical exercise protocols on physical performance related to falls in the oldest old: a randomized controlled trial. Geriatr Gerontol Int. 2016;16:492-9. https:// doi.org/10.1111/ggi.12497.

30. Ansai JH, Rebelatto JR. Effect of two physical exercise protocols on cognition and depressive symptoms in oldest-old people: a randomized controlled trial. Geriatr Gerontol Int. 2015;15:1127-34. https://doi.org/10. 1111/ggi.12411.

31. Lord SR, Lloyd DG, Nirui M, Raymond J, Williams P, Stewart RA. The effect of exercise on gait patterns in older women: a randomized controlled trial. J Gerontol A Biol Sci Med Sci. 1996;51:M64-70. https://doi.org/10.1093/ gerona/51a.2.m64.

32. Lord SR, Ward JA, Williams P, Strudwick M. The effect of a 12-month exercise trial on balance, strength, and falls in older women: a randomized controlled trial. J Am Geriatr Soc. 1995;43:1198-206. https://doi.org/10.1111/ j.1532-5415.1995.tb07394.x.

33. de Resende Neto AG, Santos MS, Silva RJS, Santana JM, Silva-Grigoletto MED. Effects of different neuromuscular training protocols on the functional capacity of elderly women. Rev Bras Med Esporte. 2018;24:140-4. https:// doi.org/10.1590/1517-869220182402167781.
34. de Resende-Neto AG, da Silva RM, Oliveira-Andrade BC, da Silva Chaves LM, LHA B, Nogueira AC, et al. Functional training in comparison to traditional training on physical fitness and quality of movement in older women. Sport Sci Health. 2020. https://doi.org/10.1007/s11332-020-00675-x.

35. Kovács E, Prókai L, Mészáros L, Gondos T. Adapted physical activity is beneficial on balance, functional mobility, quality of life and fall risk in community-dwelling older women: a randomized single-blinded controlled trial. Eur J Phys Rehabil Med. 2013;49:301-10.

36. Wolf R, Locks RR, Lopes PB, Bento PCB, Rodacki ALF, Carraro AN, Pereira G. Multicomponent exercise training improves gait ability of older women rather than strength training: a randomized controlled trial. J Aging Res. 2020;2020:6345753. https://doi.org/10.1155/2020/6345753.

37. Braga JC, de Freitas RE, dos Santos KM, Pontes da Silva R, Mota da Silva J, Junior AL, et al. Twelve weeks of high-intense interval training enhance the neuromuscular and cardiorespiratory performance of elderly. TOSSJ. 2020;13: 42-8. https://doi.org/10.2174/1875399X02013010042.

38. Carvalho MJ, Marques E, Mota J. Training and detraining effects on functional fitness after a multicomponent training in older women. Gerontology. 2009;55:41-8. https://doi.org/10.1159/000140681.

39. Caserotti $P$, Aagaard $P$, Puggaard L. Changes in power and force generation during coupled eccentric-concentric versus concentric muscle contraction with training and aging. Eur J Appl Physiol. 2008;103:151-61. https://doi.org/ 10.1007/s00421-008-0678-x.

40. Englund U, Littbrand $H$, Sondell A, Pettersson U, Bucht G. A 1-year combined weight-bearing training program is beneficial for bone mineral density and neuromuscular function in older women. Osteoporos Int. 2005; 16:1117-23. https://doi.org/10.1007/s00198-004-1821-0.

41. Freiberger E, Menz HB, Abu-Omar K, Rutten A. Preventing falls in physically active community-dwelling older people: a comparison of two intervention techniques. Gerontology. 2007:53:298-305. https://doi.org/10.1159/ 000103256.

42. Leite JC, Forte R, de Vito G, Boreham CAG, Gibney MJ, Brennan L, Gibney ER. Comparison of the effect of multicomponent and resistance training programs on metabolic health parameters in the elderly. Arch Gerontol Geriatr. 2015;60:412-7. https://doi.org/10.1016/j.archger.2015.02.005.

43. da Silva ST, Rocha SV, Vasconcelos LRC, Queiroz BM, Oliveira SC, Coutinho APP. The effect of physical exercise on the memory of elderly - an intervention study. Motriz: Rev Educ Fis. 2019. https://doi.org/10.1590/s19806574201900040020.

44. Sohng K-Y, Moon J-S, Song H-H, Lee K-S, Kim Y-S. Fall prevention exercise program for fall risk factor reduction of the community-dwelling elderly in Korea. Yonsei Med J. 2003;44:883-91. https://doi.org/10.3349/ymj.2003.44.5.883.

45. Falck RS, Davis JC, Best JR, Crockett RA, Liu-Ambrose T. Impact of exercise training on physical and cognitive function among older adults: a systematic review and meta-analysis. Neurobiol Aging. 2019;79:119-30. https://doi.org/10.1016/j.neurobiolaging.2019.03.007.

46. Hurst C, Weston KL, McLaren SJ, Weston M. The effects of same-session combined exercise training on cardiorespiratory and functional fitness in older adults: a systematic review and meta-analysis. Aging Clin Exp Res. 2019;31:1701-17. https://doi.org/10.1007/s40520-019-01124-7.

47. Levin O, Netz Y, Ziv G. The beneficial effects of different types of exercise interventions on motor and cognitive functions in older age: a systematic review. Eur Rev Aging Phys Act. 2017;14:20. https://doi.org/10.1186/s11556017-0189-z.

48. Marín-Cascales E, Alcaraz PE, Ramos-Campo DJ, Rubio-Arias JA. Effects of multicomponent training on lean and bone mass in postmenopausal and older women: a systematic review. Menopause. 2018;25:346-56. https://doi. org/10.1097/GME.0000000000000975.

49. Moreland JD, Richardson JA, Goldsmith $\mathrm{CH}$, Clase CM. Muscle weakness and falls in older adults: a systematic review and meta-analysis. J Am Geriatr Soc. 2004;52:1121-9. https://doi.org/10.1111/j.1532-5415.2004.52310.x.

50. Granacher U, Gollhofer A, Hortobágyi T, Kressig RW, Muehlbauer T. The importance of trunk muscle strength for balance, functional performance, and fall prevention in seniors: a systematic review. Sports Med. 2013;43:62741. https://doi.org/10.1007/s40279-013-0041-1.

51. Mortaza N, Abu Osman NA, Mehdikhani N. Are the spatio-temporal parameters of gait capable of distinguishing a faller from a non-faller elderly? Eur J Phys Rehabil Med. 2014;50:677-91.

52. Sheppard JM, Young WB. Agility literature review: classifications, training and testing. J Sports Sci. 2006;24:919-32. https://doi.org/10.1080/ 02640410500457109 
53. Lichtenstein E, Morat M, Roth R, Donath L, Faude O. Agility-based exercise training compared to traditional strength and balance training in older adults: a pilot randomized trial. PeerJ. 2020;8:e8781. https://doi.org/10.7717/ peerj.8781.

54. Morat M, Faude O, Hanssen H, Ludyga S, Zacher J, Eibl A, et al. Agility training to Integratively promote neuromuscular, cognitive, cardiovascular and psychosocial function in healthy older adults: a study protocol of a one-year randomized-controlled trial. Int J Environ Res Public Health. 2020 https://doi.org/10.3390/ijerph17061853.

\section{Publisher's Note}

Springer Nature remains neutral with regard to jurisdictional claims in published maps and institutional affiliations.

Ready to submit your research? Choose BMC and benefit from:

- fast, convenient online submission

- thorough peer review by experienced researchers in your field

- rapid publication on acceptance

- support for research data, including large and complex data types

- gold Open Access which fosters wider collaboration and increased citations

- maximum visibility for your research: over $100 \mathrm{M}$ website views per year

At BMC, research is always in progress.

Learn more biomedcentral.com/submissions 